\title{
Spontaneous regression of lumbar disc herniation: Conservative treatment in a case with motor deficit
}

\author{
Saliha Eroğlu Demir, Nihal Özaras, Ebru Aytekin
}

\begin{abstract}
Introduction: Conservative healing of lumbar disc herniation (LDH) exists. Most surgical studies have followed a minimum six-week trial of conservative therapy before surgical intervention. Patients who do not present with emergency surgery indications may be treated initially with conservative methods. Case Report: A case of 32-year-old female with motor deficit caused by an extruded herniated disc. Physical and medical therapy was given because she refused to undergo surgery. After the treatment, her motor deficits improved. Magnetic resonance imaging scan showed totally regression of the extruded disc. Conclusion: Although a single case cannot confirm the validity of conservative management of LDH with motor deficits, patient preference and severity of the disability from pain are important factors when choosing treatment modalities.
\end{abstract}

Keywords: Intervertebral disk displacement, Lumbosacral region, Low back pain, Neurologic manifestations, Physical therapy modalities.

Saliha Eroğlu Demir ${ }^{1}$, Nihal Özaras ${ }^{2}$, Ebru Aytekin ${ }^{3}$

Affiliations: ${ }^{1} \mathrm{MD}$, Associated Professor, Physical medicine and Rehabilitation Specialist, Bezmialem Vakif University, Physical Medicine and Rehabilitation Department, Istanbul, Turkey; ${ }^{2} \mathrm{MD}$, Associated Professor, Bezmialem Vakif University, Physical Medicine and Rehabilitation Department, Istanbul, Turkey; ${ }^{3} \mathrm{MD}$, Physical medicine and Rehabilitation Specialist, Ministry of Health, Istanbul Research and Training Hospital, Physical Medicine and Rehabilitation Clinic, Istanbul, Turkey.

Corresponding Author: Saliha Eroglu Demir, MD, Physical Medicine and Rehabilitation Department Bezmialem Vakif University Medical Faculty, Department of Physical Medicine and Rehabilitation, Istanbul, Turkey; Tel: +90 21252337 19; Fax: +90 21253323 26; Email: saliha45@yahoo.com

Received: 03 August 2012

Accepted: 07 December 2012

Published: 01 October 2013
Demir SE, Özaras N, Aytekin E. Spontaneous regression of lumbar disc herniation: Conservative treatment in a case with motor deficit. International Journal of Case Reports and Images 2013;4(10):578-581.

$$
* * * * * * * * *
$$

doi:10.5348/ijcri-2013-10-384-CR-13

\section{INTRODUCTION}

Lumbar disc herniation (LDH) is a common health problem. There have been some reports on spontaneous regression of LDH at different levels and with various clinical presentations such as myelopathy, neurological deficits, lumbar radiculopathy ascertained by magnetic resonance imaging (MRI) scan or computed tomography (CT) scan [1-9]. Since spontaneous resorption of LDH is well-known, most patients including with neurologic deficits are reluctant to disc surgery. A case of spontaneous regression of extruded disc herniation with severe motor deficit (manual muscle test $\leq 3$ ) is rare. In this report, totally regression of herniated material in a case with severe motor deficit caused by an extruded herniated disc at the $\mathrm{L} 4-\mathrm{L} 5$ level is presented.

\section{CASE REPORT}

A 32-year-old female presented for the physical medicine and rehabilitation department in March 2008 with a two-month history of low back and right leg radiating pain. The patient's history was notable for intermittent low back pain over the previous nine months after normal vaginal delivery in July 2007. Her pain had started to radiate to right leg after she lifted her baby two months ago. The patient was able to ambulate in sideways bending position. Neurological examination showed a positive straight-leg raising test (SLRT) at $40^{\circ}$ on the right 
side. The SLRT was negative on the left side. On manual muscle test, muscle weakness was found in the right leg: tibialis anterior was $3 / 5$, extensor hallucis longus was $2 / 5$. The right patella tendon reflex was normal. Hypoesthesia was noted over the medial calf and dorsum of the right foot. Magnetic resonance imaging (MRI) scan showed large extruded disc herniation on the right side at the L4L5 intervertebral disc level compressing the spinal nerve and the dural sac (Figure 1). The patient was a medical doctor and aware of the risk of neurological impairment. She refused surgical intervention and preferred to take conservative treatment. She accepted to be prescribed ibuprofen, but refused any other medication because she insisted on breastfeeding her child. Patient was appointed 14 sessions of physical therapy including conventional transcutaneous electrical nerve stimulation (TENS) (20 minutes), a 1-Mhz ultrasound (10 minutes, intensity $1 \mathrm{~W} / \mathrm{cm}^{2}$, continue mode), interference current vacuum therapy (10 minutes, $50 \mathrm{~Hz}$ frequency, pulse mode), hot pack (20 minutes), back exercises and prescribed lumbosacral corset. The patient wore lumbosacral corset for three weeks and stayed active with it. She continued working and taking care of her child after the work. She was very careful about possible triggering movements for pain because she knew biomechanics of low back. She tried to do every movement without triggering pain. After 14 physical therapy session, the patient was able to ambulate normally. Straight-leg raising test was positive at $60^{\circ}$ and muscle strength of tibialis anterior and extensor hallucis longus were $4 / 5$ and $3 / 5$ on the right leg, respectively. She still had right leg radiating pain and low back pain, but not the same magnitude after the therapy (Visual analog scale for pain: before treatment 9, after treatment 4). She was offered surgical intervention again, but she refused. She was followed with serial neurological examinations. During this period, her pain gradually improved.



Figure 1: Sagittal and axial images of extruded disc hernia demonstrated in magnetic resonance imaging of the lumbar spine.
After 18 months, the patient was still complaining intermittent right leg radiating pain. The SLRT was negative and there was weakness of extensor hallucis longus muscle (4/5). Hypoesthesia was noted over the dorsum of the right foot. A second lumbosacral MRI scan was done at this time. It revealed total regression of the extruded disc fragment at the L4-L5 level without compression of dural sac and L5 root, but a protruded L5S1 herniated disc (Figure 2).

At the end of the second year, she had no pain at resting or with daily activities. She described intermittent radiating pain with or without back pain associated with seasonal factors such as rainy days.

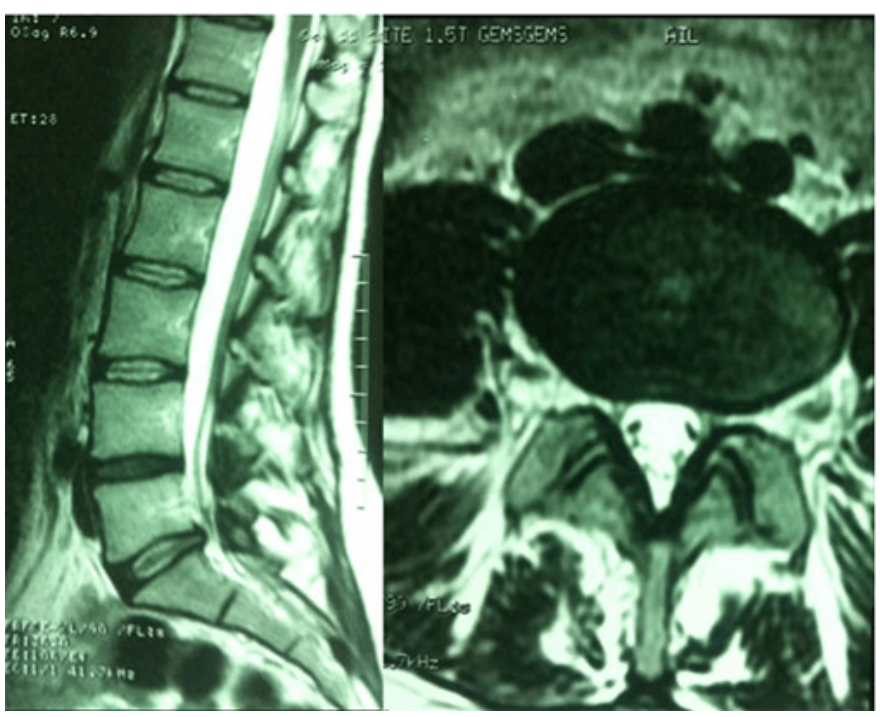

Figure 2: Follow-up magnetic resonance imaging (sagittal and axial) showing regression of $\mathrm{L}_{4}-\mathrm{L} 5$ disc herniation.

\section{DISCUSSION}

The natural course of LDH is benign in many cases as herniated nucleus pulposus regresses spontaneously in time and symptoms will improve in most patients with conservative management alone $[10,11]$. There are three hypotheses explaining spontaneous regression. The first hypothesis is dehydration of herniated disc. This states that herniated fragment would disappear due to gradual dehydration and shrinkage. The second hypothesis, 'retraction of herniated disc', means that herniated disc retracts back into the intervertebral space. The third hypothesis, inflammatory reaction and neovascularization', states that extruded material is recognized as a foreign body and induces an inflammatory reaction by autoimmune system resulting neovascularization, enzymatic degradation, and macrophage phagocytosis $[1-4,6,12]$. It is possible that all three mechanisms play a role in regression of herniated tissue. Many factors related to resorption process have been recognized: penetration through posterior 
longitudinal ligament, size of herniation and existence of cartilage and anulus fibrosus tissue in herniated material [10]. Some authors reported that patients younger than 40 years old and migrating or extruding type herniations had a higher spontaneously regression potential $[2,6$, 13]. In their follow-up of disc herniation resorption on MRI scan, Autio et al. were reported that higher baseline scores for enhancement thickness, higher migration according to the Komori classification, and age category 41-50 years were associated with a higher resorption rate [10].

Motor and sensory deficits are present in 50-90\% of patients with LDH [14]. Patients with paresthesias or motor weakness should be observed very closely. There seems to be consensus that surgery is indicated in patients with persistent neuromotor deficit, or severe radiculopathy with a positive SLRT and imaging demonstrating $\mathrm{LDH}$ at the nerve root level correlating with the patient's examination findings [11, 15]. Most surgical studies have followed a minimum six-week trial of conservative treatment before surgical intervention [11]. Surgical treatment may result in faster relief of symptoms and earlier return to function than conservative treatments. However, long-term results appear to be equally effective $[16,17]$.

Conservative treatment for LDH and radiculopathy is primarily aimed at pain reduction by analgesics or by reducing pressure on the nerve root [15]. It includes medications, physical therapy, corsets and lumbar injection. Physical therapy is an important conservative treatment choice of LDH. Many physical modalities including TENS, Ultrasound, laser, traction, exercise, massage could be chosen. The effects of physical modalities are various such as enhanced microcirculation, local release of neurotransmitters such as serotonin, increased activity of small non-myelinated C-fibers, muscle relaxation, increased local blood flow [18] In a systematic review, Hahne et al. reported that many of the intervention and comparison treatments including advice, medication, traction, stabilization exercises, physical therapy, manipulation, laser, ultrasound, corsets and multimodal inpatient program were equivalent [15]. Significant pain relief and improvement of function was reported by a combination treatment of physical modalities [18].

The efficacy of conservative management of LDH in the presence of severe motor deficit is reported in the present case. Patient was referred to a spinal surgeon. But her choice for the treatment was conservative and we planned combined physical therapy program and observed her neurologic deficits closely. The potential for the regression was higher because she was young and extruding type herniation was revealed. At the end of physical therapy, her pain was tolerable and there was obvious neurological improvement. At that period, we considered that the mechanism of this improvement could be the dehydration of herniated material.

\section{CONCLUSION}

Although a single case cannot confirm the validity of nonsurgical management of lumbar disc herniation with severe motor deficits; patient preference, symptom duration and the severity of the disability from the pain are important factors when choosing treatment modalities.



\section{Author Contributions}

Saliha Eroğlu Demir - Substantial contributions to conception and design, Acquisition of data, Drafting the article, Revising it critically for important intellectual content, Final approval of the version to be published

Nihal Özaras - Substantial contributions to conception and design, Acquisition of data, Drafting the article, Revising it critically for important intellectual content, Final approval of the version to be published

Ebru Aytekin - Substantial contributions to conception and design, Acquisition of data, Drafting the article, Revising it critically for important intellectual content, Final approval of the version to be published

\section{Guarantor}

The corresponding author is the guarantor of submission.

\section{Conflict of Interest}

Authors declare no conflict of interest.

\section{Copyright}

(C) Saliha Eroğlu Demir et al. 2013; This article is distributed under the terms of Creative Commons attribution 3.0 License which permits unrestricted use, distribution and reproduction in any means provided the original authors and original publisher are properly credited. (Please see www.ijcasereportsandimages.com/ copyright-policy.php for more information.)

\section{REFERENCES}

1. Ryu SJ, Kim IS. Spontaneous regression of a large lumbar disc extrusion. J Korean Neurosurg Soc 2010;48(3):285-7.

2. Chang CW, Lai PH, Yip CM, Hsu SS. Spontaneous regression of lumbar herniated disc. J Chin Med Assoc 2009;72(12):650-3.

3. Gezici AR, Ergun R. Spontaneous regression of a huge subligamentous extruded disc herniation: short report of an illustrative case. Acta Neurochir (Wien) 2009;151(10):1299-300.

4. Sabuncuoglu H, Ozdogan S, Timurkaynak E. Spontaneous regression of extruded lumbar disc herniation: report of two illustrative case and review of the literature. Turk Neurosurg 2008;18(4):392-6.

5. MaigneJY, Rime B, Deligne B. Computed tomographic follow-up study of forty-eight cases of nonoperatively treated lumbar intervertebral disc herniation. Spine 
(Phila Pa 1976) 1992;17(9):1071-4.

6. Komori H, Shinomiya K, Nakai O, Yamaura I, Takeda S, Furuya K. The natural history of herniated nucleus pulposus with radiculopathy. Spine (Phila Pa 1976) 1996;21(2):225-9.

7. Gurkanlar D, Aciduman A, Kocak H, Gunaydin H. Spontaneous regression of lumbar disc herniations at different levels and times in a patient: A case report. Turk Neurosurg 2005;15(1):18-22.

8. Kasimcan O, Kaptan H. Lomber Disk Hernisinde Spontan Regresyon (Spontaneous Regression of Lumbar Disc Hernia: Original Image). Turkiye Klinikleri J Med Sci 2008;28(3):422-4.

9. Torun F. Spontaneous Regression of an Extruded Lumbar Disc Herniation: A Case Report. J Neurol Sci [Turk] 2007;24(10):88-90.

10. Autio RA, Karppinen J, Niinimaki J, et al. Determinants of spontaneous resorption of intervertebral disc herniations. Spine (Phila Pa 1976.) 2006;31(11):1247-52.

11. Gregory DS, Seto CK, Wortley GC, Shugart CM. Acute lumbar disk pain: navigating evaluation and treatment choices. Am Fam Physician 2008;78(7):835-42.

12. Slavin KV, Raja A, Thornton J, Wagner FC Jr. Spontaneous regression of a large lumbar disc herniation: report of an illustrative case. Surg Neurol 2001;56(5):333-6.

13. Meydan Ocak F, Karaaslan M, Tutar I, Konuralp N, Güzelant A, Ozguzel H. Lomber Disk Hernilerinde
Konservatif Tedavi Etkinliginin Klinik Parametreler ve Manyetik Rezonans Görüntüleme Yöntemi ile Degerlendirilmesi (Evaluation of the Efficacy of Conservative Therapies with Clinical Parameters and Magnetic Resonance Imaging in Lumbar Disc Herniations). Turk J Phys Med Rehab 2007;53:10812.

14. Weinstein JN, Lurie JD, Tosteson TD, et al. Surgical vs nonoperative treatment for lumbar disk herniation: the Spine Patient Outcomes Research Trial (SPORT) observational cohort. JAMA 2006;296(20):2451-9.

15. Jacobs WC, van Tulder M, Arts M, et al. Surgery versus conservative management of sciatica due to a lumbar herniated disc: a systematic review. Eur Spine J 2011;20(4):513-22.

16. Hahne AJ, Ford JJ, McMeeken JM. Conservative management of lumbar disc herniation with associated radiculopathy: a systematic review. Spine (Phila Pa 1976) 2010;35(11):E488-504.

17. Schoenfeld AJ, Weiner BK. Treatment of lumbar disc herniation: Evidence-based practice. Int J Gen Med 2010;3:209-14.

18. Pieber K, Herceg M, Kienbauer M, et al. Combination treatment of physical modalities in the treatment of musculoskeletal pain syndromes: a prospectivecontrolled study. European Journal Translational Myology 2010;1(4):157-165.
Access full text article on other devices

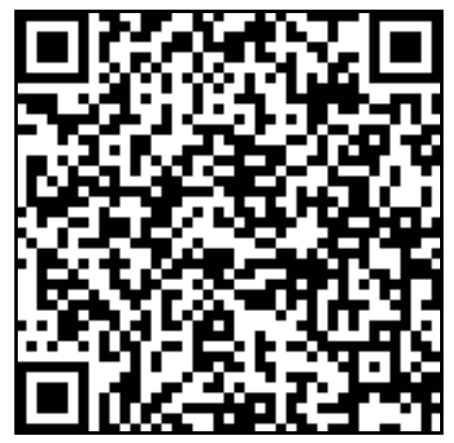

Access PDF of article on other devices

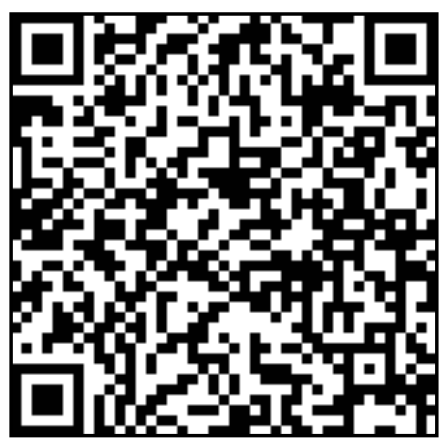

